\title{
Poemas de Life in Handkerchiefs / A Vida em Lenços
}

The overview of this work is as follows:

Life in Handkerchiefs is a 79-page image-text book with feminist charm (yes; it's possible), a literary-visual hybrid. It has the look of a gift book and the ethos of empathetic critique.

Life in Handkerchiefs, each $81 \frac{1}{2} \times 11$ inches, uses vintage handkerchiefs along with paper, string, lace, crocheted edging, decorative notions, origami paper, and it proposes a chronological "survey" of female life via hankies and responsive poems and meditations. Each page is one collage-poem in color, connecting text and image. This book is varied in tone, ranging from jaunty, somber, droll, aphoristic, rueful, yearning, ironic, critical, suspicious, compassionate. It features strong thematic repeats in female striving, many bizarre vagaries of "the feminine" and "the quotidian," female body thoughts, female friendship, family, mother-daughter relationships, historical contexts, gender politics, holidays and inner life, growing up female, and (a frequent topic in all my work) a sense of the mystery and oddity of existence. Not all these themes occur in this selection. Life in Handkerchiefs is like a gift box of handkerchiefs, telling surprising backstories, suggesting wry implications, and illuminating some handkerchief semiotics. Given the various narratives and feelings behind and within female lives and given their visual expressions via little scraps of fabric "texting" us with memories and analyses, this book is poised at the generative intersection of art and literature. 
Este trabalho pode ser resumido da seguinte forma:

A vida em lenços é um livro de imagem-texto com 79 páginas e charme feminista (sim, isso é possível!), um literário-visual híbrido. Tem a aparência de um livro para prenda e o espírito da crítica empática.

A vida em lenços. Cada lenço tem $21 \mathrm{~cm} \times 28 \mathrm{~cm}$. São lenços vintage combinados com papel, fio, rendas, bainhas em crochet, conceitos decorativos, papel de origami. Propõe-se uma "pesquisa" cronológica da vida feminina por meio de lenços, poemas que sejam sensíveis e meditações. Cada página é um poema-collage a cores, ligando texto e imagem. Este livro é multifacetado no tom, passando de alegre a sombrio, de humorístico a aforístico, de pesaroso a ansioso, de irónico a crítico, de desconfiado a solidário. Apresenta fortes repetições temáticas de esforço feminino, muitas fantasias bizarras sobre "o feminino" e "o quotidiano", pensamentos sobre o corpo feminino, a amizade feminina, a família, as relações mãe-filha, os contextos históricos, as políticas de género, festividades e vida interior, crescer como mulher, e (um tópico frequente em todo o meu trabalho) um sentido de mistério e estranheza da existência. Nem todos esses temas aparecem nesta seleção. $A$ vida em lenços é como uma caixa de lenços para oferecer como prenda, que contam histórias de fundo surpreendentes, sugerem implicações irónicas e iluminam a semiótica do lenço. Dadas as várias narrativas e emoções que subjazem e preenchem as vidas femininas; dadas as suas expressões visuais por meio de pequenos pedaços de tecido que nos "enviam mensagens" com memórias e análises, este livro situa-se na intersecção geradora da arte e da literatura.

Trad. Ana Luísa Amaral 


\section{Never gender}

Gender was never so simple as hot pink, cute blue, and dear darling deer. (The Art of the Deer.) In fact, this hanky was made of completely artificial fabric, perhaps some kind of rayon. Which is why it will never go flat (straight) and will always have permanent creases in it, no matter how much it was ironed. The images are badly printed; the ink does not take, and things even seem ugly and painfully arch. In short, a failure: given that they clearly were made to be cute. Doctoring it (not medicalizing-I said "doctoring"--) with several extra colors is the happier path. Leaping beyond the given, and between.

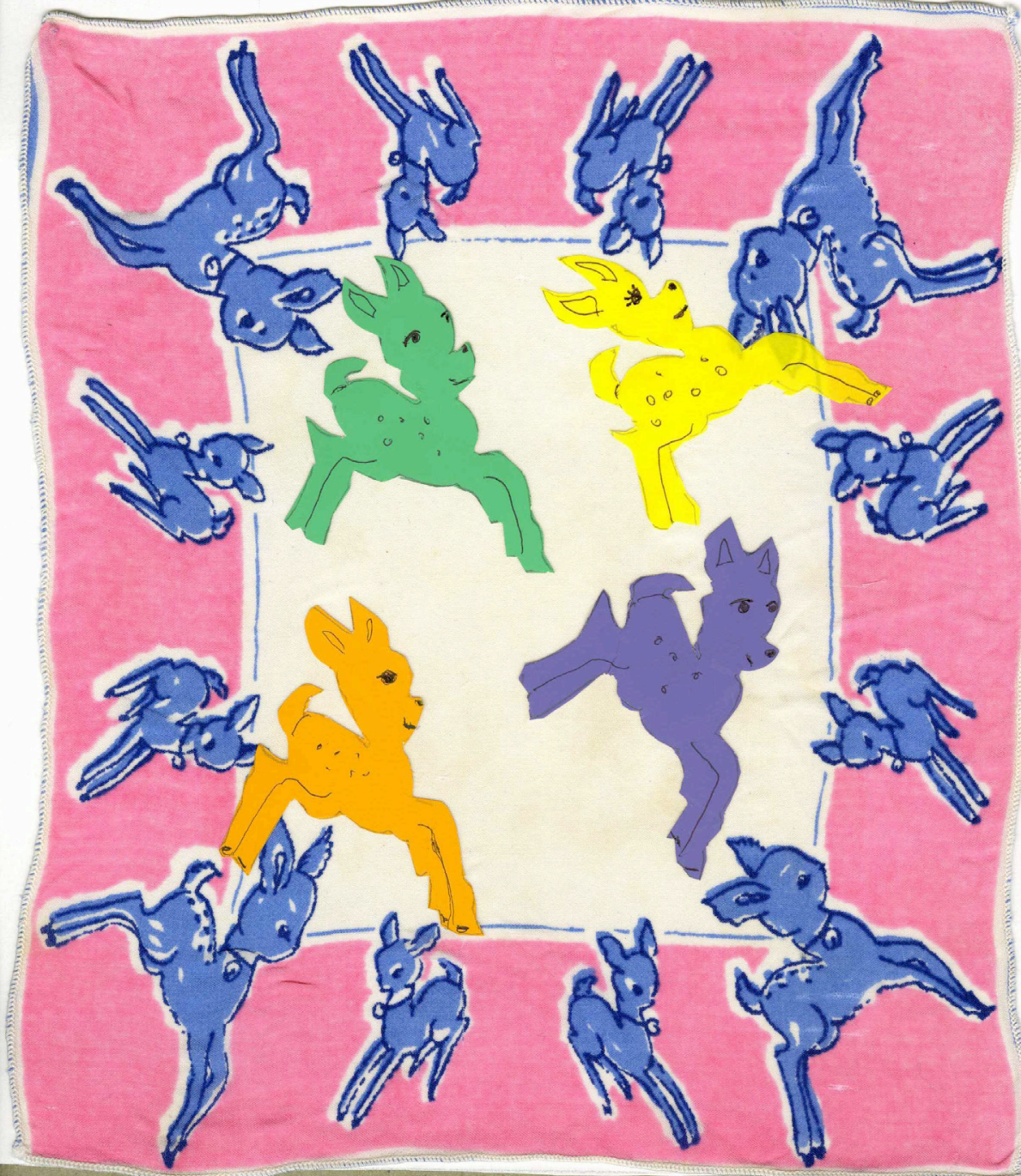




\section{Nunca o género}

Nunca o género foi tão simples como o rosa muito quente, o bonito azul, o amado veado adorado (A Arte do Veado). De facto, este lenço foi feito de tecido totalmente artificial, talvez um tipo de raiom. Por isso nunca ficará liso (direito) e terá sempre vincos permanentes, por mais que seja passado a ferro. As imagens não estão muito bem impressas, a tinta não pegou e as coisas parecem até feias, dolorosamente curvas. Em resumo: um fiasco: sobretudo porque elas foram criadas para serem bonitas. Remediar (não de medicamento - eu disse remediar) com várias outras cores será o caminho mais feliz. Saltar por sobre e para lá do habitual, e pelo meio dele.

Trad. Ana Luísa Amaral 


\section{The quilt}

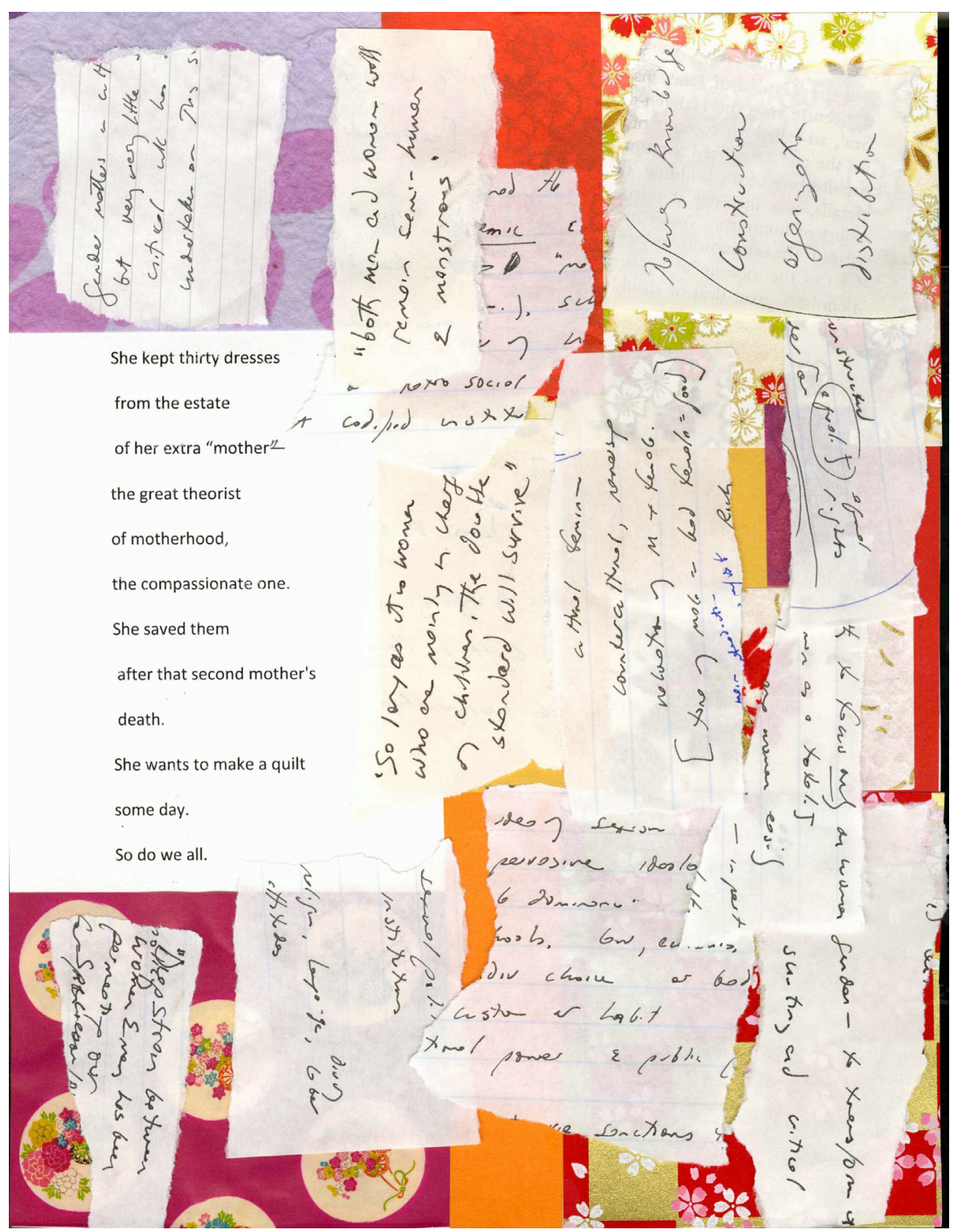


REDE INTERNACIONAL LYRACOMPOETICS

Rachel Blau DuPlessis

\section{A colcha}

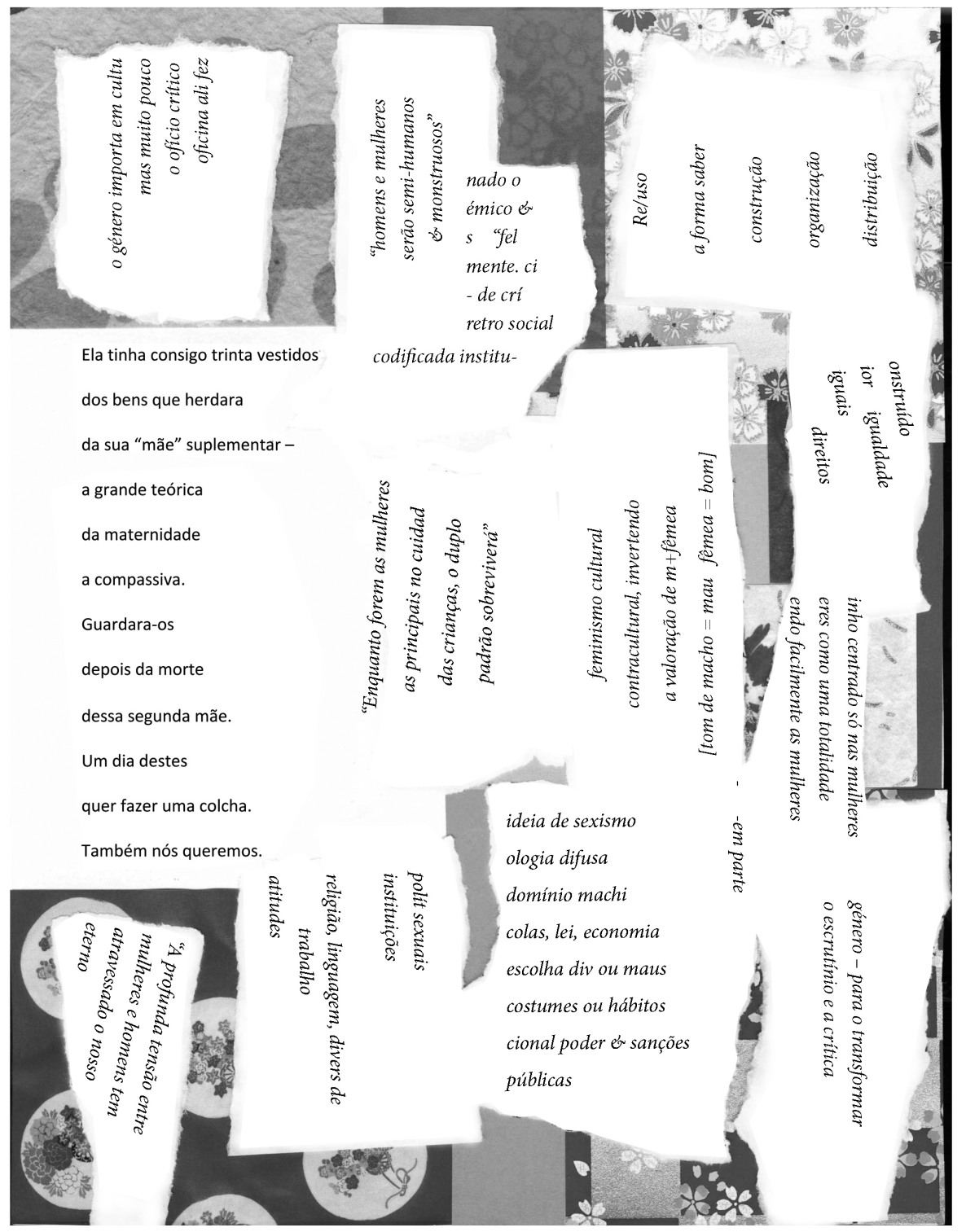

[Arranjo gráfico de Isabel Carvalho]

Trad. Ana Luísa Amaral 


\section{She was sick}

She was sick and staying here I got into bed with her to tell her a concocted story. She emerged swaying.

She was pale and light. She was two dimensional and translucent.

She was a piece of paper. I was stunned that her pubic hair had gone completely white I said, "You don't look so bad." I told a lie that night.

Lying that night
on the bed of
bad and good. Look!
speckled red and white
this body and its skin.
The brain is pale but
arabesque, pubis
still plump.
I was stunned
at all the paper
semi-lucent or thick
it took to tell
any tale at all,
sex, love, pain,
time swaying
well, or poorly.
Or tripped
and sprawled
again.

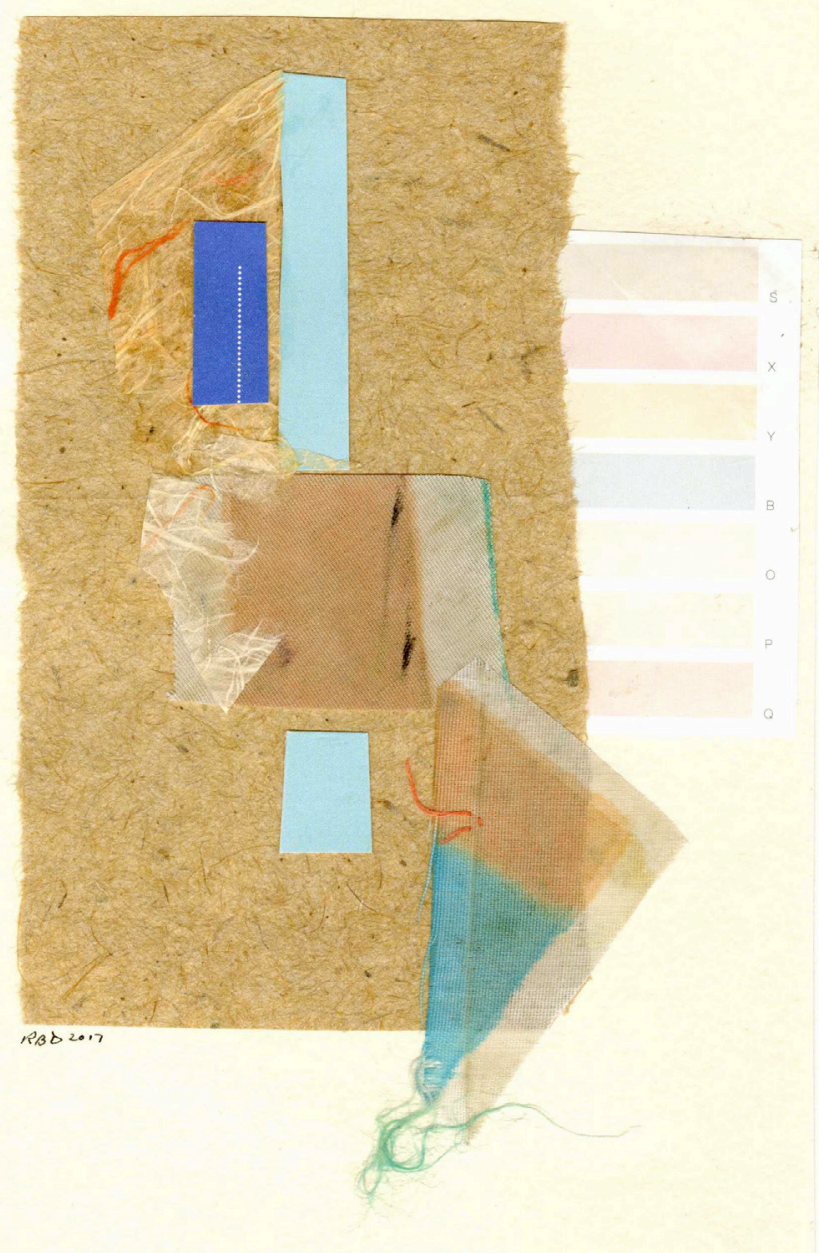




\section{Ela estava doente}

Ela estava doente

e ficara aqui, deitei-me com ela para lhe contar uma história falsa. Ela assomou oscilante.

Era pálida e leve.

A duas dimensões e translúcida.

Era um pedaço de papel.

Fiquei espantada por os seus pelos púbicos

terem ficado completamente brancos, e disse-lhe "Não pareces

estar muito mal".

Contei uma mentira nessa noite.

Deitada esta noite

na cama do bem e do mal. Olha!

manchado a vermelho e branco

este corpo e a sua pele.

O cérebro é pálido mas

arabesco, a púbis, carnuda ainda.

Fiquei espantada de ver todo o papel semi-luzente ou espesso que é preciso para dizer qualquer história de sexo, de amor, de sofrimento, o tempo oscilando muito, ou pouco.

Ou tropeçando e alastrando outra vez. 


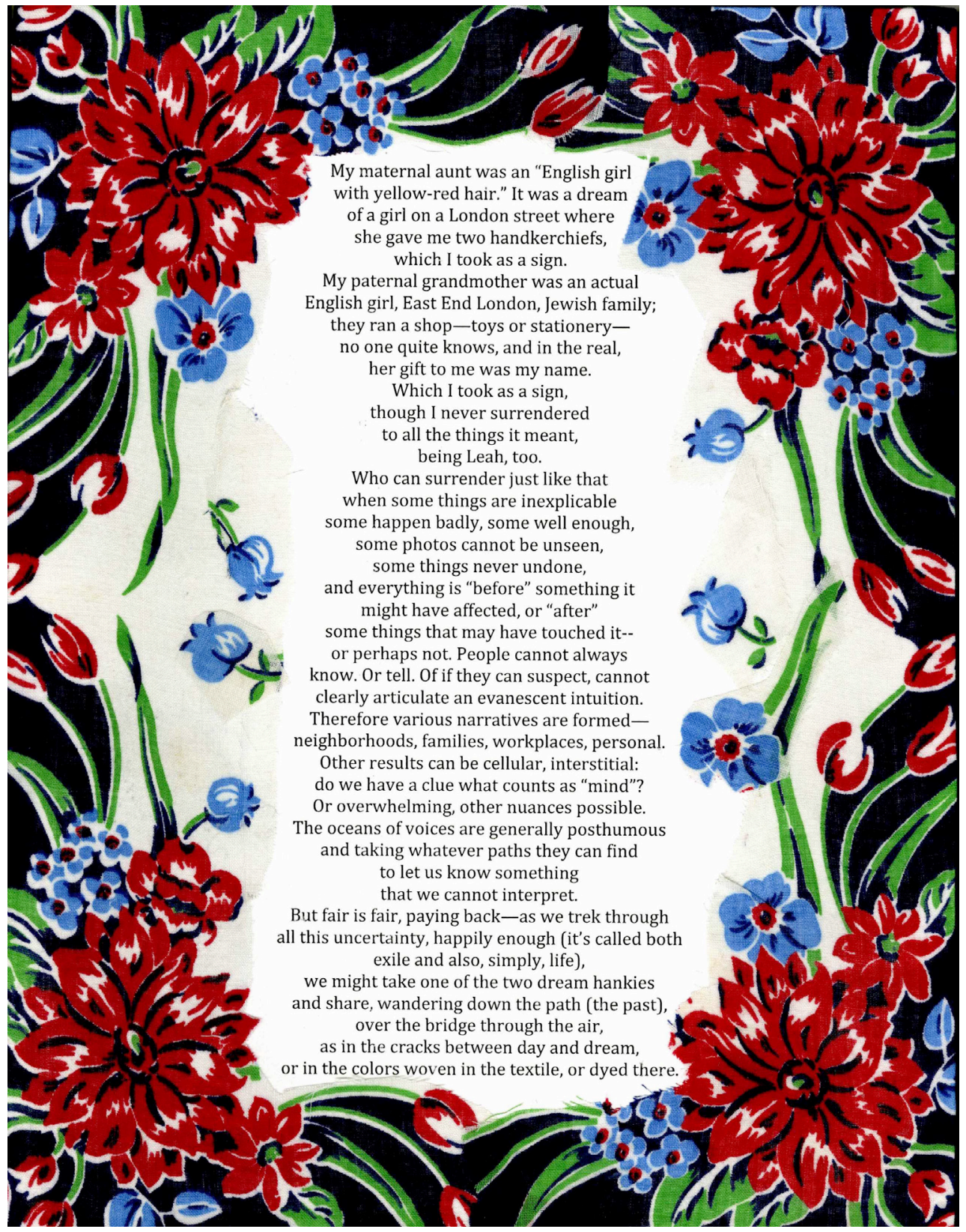




\section{A minha tia materna}

A minha tia materna era uma "rapariga inglesa de cabelo ruivo". Era um sonho de rapariga numa rua de Londres onde me deu dois lenços, que entendi como um sinal. A minha avó paterna era uma verdadeira rapariga inglesa, do East End de Londres, família judaica; tinham uma loja - de brinquedos, ou uma papelaria ninguém sabe ao certo, e na verdade a prenda que me deu foi o meu nome.

Que eu entendi como um sinal, embora nunca me rendesse a tudo o que ele significava, sendo Lia, também.

Quem pode render-se assim de repente quando algumas coisas são inexplicáveis, umas acontecem mal, outras mais ou menos, há fotografias que não podem deixar de ser vistas, coisas que não podem ser desfeitas, e tudo se passa "antes" de algo poder ser alterado, ou "depois" de coisas que foram tocadas ou talvez não. Nem sempre se consegue saber. Nem dizer. Ou se é possível suspeitar, não se consegue verbalizar uma intuição evanescente.

Por isso se formam narrativas várias vizinhanças, famílias, locais de trabalho, pessoais. Outros resultados podem ser celulares, intersticiais: Fazemos alguma ideia do que se considera "mente"? Ou do que é esmagador, outras gradações possíveis.

Os oceanos de vozes são geralmente póstumos e seguem pelos caminhos que melhor encontram para nos dizer algo que não podemos interpretar.

Mas o que é justo, é justo, a paga - à medida que trilhamos por toda esta incerteza, felizes que chegue (a isso chama-se 


\section{exílio e também, simplesmente, vida), podemos seguir por um dos dois lenços do sonho \\ e partilhar, errando pela estrada (o passado), por sobre a ponte pelo ar, como nas fendas entre dia e sonho, ou nas cores tecidas no tecido, ou nele tingidas.}

Trad. Ana Luísa Amaral

* Rachel Blau DuPlessis é poeta, crítica e explora a collage no seu trabalho. O seu livro mais recente é Late Work (Black Square Editions, 2020) da série Traces, with Days, incluindo Days and Works (Ahsahta Editions, 2017) e Around the Day in 80 Worlds (BlazeVOX, 2018). Os poemas-collage impressos são "Churning the Ocean of Milk" (2014, http://www.alligatorzine.be), Graphic Novella (Xexoxial Editions, 2015) e, mais recentemente, NUMBERS (Materialist Press, 2018). A sua carreira como poeta e crítica integra uma série de livros sobre género e poética, incluindo a trilogia The Pink Guitar, Blue Studios e Purple Passages. Co-organizou várias antologias e organizou The Selected Letters of George Oppen. Vive em Filadélfia, nos EUA. 